\title{
Effects of Cutting Tool Parameters on Vibration
}

\author{
Mehmet Alper Ince and İlhan Asiltürk \\ University of Selcuk, Faculty of Engineering, Konya, Turkey.
}

\begin{abstract}
This paper presents of the influence on vibration of Co28Cr6Mo medical alloy machined on a CNC lathe based on cutting parameters (rotational speed, feed rate, depth of cut and tool tip radius). The influences of cutting parameters have been presented in graphical form for understanding. To achieve the minimum vibration, the optimum values obtained for rpm, feed rate, depth of cut and tool tip radius were respectively, $318 \mathrm{rpm}, 0.25 \mathrm{~mm} / \mathrm{rev}, 0.9 \mathrm{~mm}$ and $0.8 \mathrm{~mm}$. Maximum vibration has been revealed the values obtained for rpm, feed rate, depth of cut and tool tip radius were respectively, $636 \mathrm{rpm}, 0.1 \mathrm{~mm} / \mathrm{rev}, 0,5 \mathrm{~mm}$ and $0.8 \mathrm{~mm}$.
\end{abstract}

\section{Introduction}

Vibration is a repetitive, periodic, or oscillatory response of a mechanical system. The rate of the vibration cycles is termed "frequency." Repetitive motions that are somewhat clean and regular, and that occur at relatively low frequencies, are commonly called oscillations, while any repetitive motion, even at high frequencies, with low amplitudes, and having irregular and random behavior falls into the general class of vibration [1].

In a machining operation, vibration is problem. Vibration affects the machining performance and in particular, the surface finish and tool life. In all the cutting operations like turning, drilling and milling, vibrations occur in the machining due to a dynamic motion between the cutting tool and the work piece.

The vibration which occurs in most machines, vehicles, structures, buildings and dynamic systems is undesirable, not only because of the resulting unpleasant motions and the dynamic stresses but also because of the noise produced. Noise is generally considered to be unwanted sound, and since sound is produced by some source of motion or vibration causing pressure changes which propagate through the air or other transmitting medium, vibration control is of fundamental importance to sound attenuation. Vibration analysis of machines and structures is therefore often a necessary prerequisite for controlling not only vibration but also noise [2], [3].

Vibration control system for turning operation uses a closed-loop feedback circuit which measures the relative vibration between the cutting tool and the work piece [4]. There have been many investigations on vibration prediction and controlling based on periodic measurements of various machining conditions using accelerometer and active vibration controller.

Two generic techniques used for solving these vibration control problems are modifying stiffness or the fundamental natural frequency of the specified components/subsystems, and their damping [5].

There have been many investigations on vibration prediction and control in turning. An integrated vibration avoidance and contouring error compensation algorithm is used for multi-axis CNC machine tools [6]. They developed an integrated method which shapes the trajectory commands in such a way that they do not excite the structural modes.

Based on active and passive damping treatments, different models are developed to avoid the machine tool structure vibrations. A computational-theoretical model was developed to represent a structural system with Coulomb damping having two degrees of freedom [7]. Approximately 85 percent of the passive damping treatments in actual applications are based on viscoelastic materials [8]. They worked on the cutting tool vibrations and control of cutting tool vibration using a damping pad made up of neoprene.

Devin and Osadchii [9] proposed a new tool design with an increased vibration-damping ability, which includes special elements made of damping materials to reduce vibration amplitude and surface roughness.

The cutting-force based vibration analysis can be done to ascertain the effect of the tool entering angle on tool vibration and tool life in a titanium alloy milling operation [10]. The vibration signals of carbide tool are monitored with the help of accelerometer and these signals then send to data acquisition system and a portable computer. The main purpose of this vibration analysis is to find the features revealing tool wear. Wavelet Packet decomposition is used to find out feature frequency band which reveals tool wear. The high degree of correlation between selected band energy, energy entropy, time-domain features and tool wear are observed. Hence, it shows the effectiveness of the proposed model 
that facilitates machine performance and reliability estimation in terms of tool life and tool wear.

The excessive wear on cutting tools leads to distortions in dimension of manufactured components. At the same time it increases scrapped levels thereby incurring additional costs. Therefore, it is crucial to detect and monitor the wear on a cutting tool in most metal cutting processes and several research efforts have done to develop on-line tool condition monitoring systems. In online metal cutting tool condition monitoring, the cutting force (Static and Dynamic) analysis and vibration analysis is done for tool wear monitoring [11]. The main purpose of this study was to develop a Tool Condition Monitoring System based on analytical modelling of online sensor signals. The results shows that the cutting forces in Z-direction and the vibration signatures were most sensitive to tool wear.

Puertas [12] state vibration can be measured in terms of peak acceleration, r.m.s value of velocity, peak to peak displacement. Ghani [13] presented a study of tool life, surface finish and vibration, while turning nodular cast iron using ceramic tool. They found that surface finish was to be almost constant with the progression of the flank wear under different cutting conditions Bonifacio [14] presented a study on correlating tool wear, tool life, surface roughness and tool vibration in finish turning with coated carbide tools. They concluded that the feed didn't influence the vibrational signal and had a little effect on surface roughness. Thomas [15] studied the effect of tool vibration on surface roughness during lathe dry turning process on mild carbon steel samples at different levels of speed, feed, depth of cut, tool nose radius, tool length and work piece length. Safeen [16] studied the effect of cutting tool vibration on surface roughness of work piece in dry turning operation. The surface roughness of the work piece is proportional to cutting tool acceleration. This effect interact with other independent variable such feed rate, depth of cut, speed. Surface roughness of work piece increases parallel to the tool vibration with increasing tool over hang.

Ahmed Syed Adnan and Sathyan Subbiah [17] have observed reduction in cutting forces and feed forces when transverse vibrations are applied. Chip thickness is also reduced and surface finish is improved upon application of vibration. This study investigates vibrations that are applied along the cutting edge and perpendicular to the cutting velocity.

Chen et al. [18] have present on reliability estimation for cutting tools based on logistic regression model using vibration signals. The three steps of new reliability estimation approach for cutting tools are as follows. First, on-line vibration signals of cutting tools are measured during the manufacturing process. Second, wavelet packet (WP) transform is employed to decompose the original signals and correlation analysis is employed to find out the feature frequency bands which indicate tool wear. Third, correlation analysis is also used to select the salient feature parameters which are composed of feature band energy, energy entropy and time-domain features. Finally, reliability estimation is carried out based on logistic regression model. The approach has been validated on a NC lathe. Under different failure threshold, the reliability and failure time of the cutting tools are all estimated accurately.

Wang et al. [19] have present on a theoretical and experimental investigation of the tool-tip vibration and its influence upon surface generation in single-point diamond turning (SPDT). In the present study, two characteristic peaks (twin peaks) are identified and found to be corresponding to the tool-tip vibrations by power spectrum density (PSD) analyses. The vibrations possess the features of small amplitude but high frequency. A physical model is proposed to capture the dominant factor based on the characteristic and it reveals that the twin peaks are attributed by the impact between the tool tip and workpiece and the process damping effect. Hence, a geometric model of surface roughness is proposed to take account of tool-tip vibration and it is verified through a series of experiments.

Marcus et al. [20] have studied the vibration reduction using passive absorption system with Coulomb damping. This research aims at investigating the possibility of using the Coulomb damping, mainly to lessen they vibrations of structures submitted to human loadings. The great advantage in using this type of damping is that we can easily obtain high levels of damping with values well controlled and adjusted to the need of the project. A computational-theoretical model was developed to represent a structural system with Coulomb damping, containing two degrees of freedom. In order to calibrate this model some experimental tests were carried out with a cantilever beam. A parametric study was performed after the theoretical- computational model had been adjusted. The results indicate that the system is only applicable to some situations, and care should be taken in the design.

Prediction of optimum cutting parameters and operating conditions for the annealed Co28Cr6Mo ASTM F 1537 steel that has low machinability, high mechanical properties, is resistant against corrosion and temperature and generally used as prosthesis in medical field is considered as a significant problem that needs to be tackled by the manufacturing experts in the related field. In this study involves the influence of rotational speed, feed rate, depth of cut and tool tip radius on vibration was determined during machining of Co28Cr6Mo medical alloy. A computer numerical controlled (CNC) machine is used for machining Co28Cr6Mo medical alloy in the present study.

\section{Machining conditions and vibration measurements}

In the experimental study an annealed Co28Cr6Mo ASTM F 1537 steel having hardness of 40 HRC was used. The specimen with dimensions of $\varnothing 50 \times 500 \mathrm{~mm}$ was prepared. Turning process was carried out on a TC25-L type Sogotec $\mathrm{CNC}$ lathe and vibration values were measured on a Kistler 8692C50 model accelerometer and Kistler 5134 B Charge Amplifier device. The tests were conducted under dry machining conditions and in every test a new cutting bit was used to machine longitudinally along the work-piece. The tool holder used was MTJNR- 
L 2525 M16, cutting bits were TNMG 160404, 160408, 160412 MT form produced by Taegutec company and cladded with TiCN by the PVD method and at the quality of TT 8020. With the recommendations from the manufacturer cutting parameters given on Table 1 and the experimental set up is shown in Fig. 1.
In this study, a total of 81 physical experiments were conducted. The first parameter column of the table shows the $\operatorname{rpm}(\mathrm{n})$, the second column gives feed rate (f), the third column is for depth of cut (a) and the last column lists the tool tip radius ( $\mathrm{r}$ )

Table 1. Cutting parameters and their levels

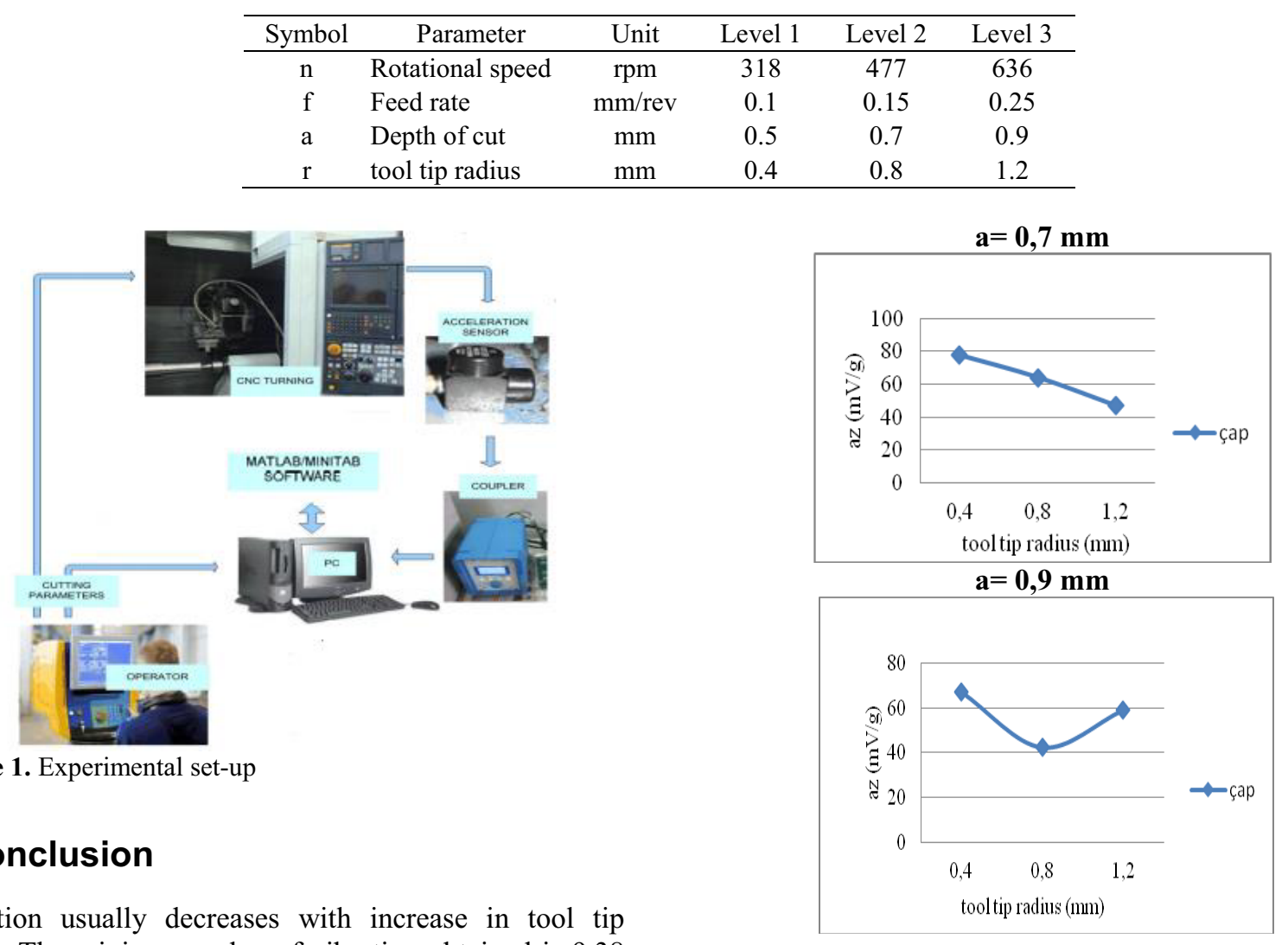

Vibration usually decreases with increase in tool tip radius. The minimum value of vibration obtained is 9.38 $\mathrm{mV} / \mathrm{g}$ at $\mathrm{n}=318 \mathrm{rpm}, \mathrm{f}=0,25 \mathrm{~mm} / \mathrm{rev}, \mathrm{a}=0,9 \mathrm{~mm}$ and $\mathrm{r}=$ $0.8 \mathrm{~mm}$. Maximum value of vibration is $93.15 \mathrm{mV} / \mathrm{g}$ at $\mathrm{n}=636 \mathrm{rpm}, \mathrm{f}=0,1 \mathrm{~mm} / \mathrm{rev}, \mathrm{a}=0,5 \mathrm{~mm}$ and $\mathrm{r}=0.8 \mathrm{~mm}$

The relationship between cutting speed and vibration is inversely proportional. Generally, increasing the cutting speed decreases the vibration. The relationship between feed rate and vibration is proportional. Generally, increasing the feed rate increases the vibration. The relationship between depth of cut and vibration is proportional. Generally, increasing the depth of cut increases the vibration. The relationship between tool tip radius and vibration is inversely proportional. Generally, increasing the tool tip radius decreases the vibration. For example, in Fig. 2, graphs of vibration are shown in the tool tip radius $(0,4-0,8-1,2 \mathrm{~mm}), \mathrm{n}=477 \mathrm{rev} / \mathrm{min}, \mathrm{f}=$ $0,15 \mathrm{~mm} / \mathrm{rev}$, and $\mathrm{a}=0,5-0,7-0,9 \mathrm{~mm}$.

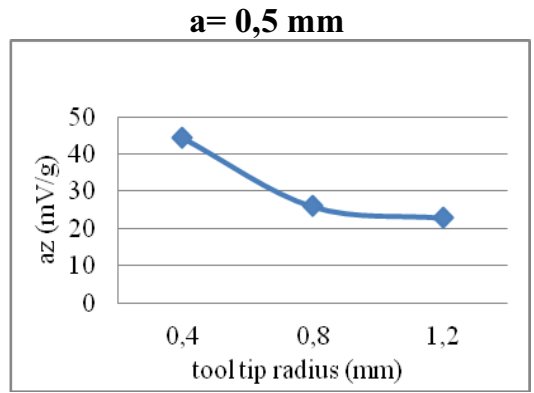

Figure 2. Graphs of Vibration for $n=477 \mathrm{rpm}, \mathrm{f}=0,15 \mathrm{~mm} / \mathrm{rev}$

$\mathrm{n}=477 \mathrm{rev} / \mathrm{min}, \mathrm{f}=0.15 \mathrm{~mm} / \mathrm{rev}$, and $\mathrm{a}=0,5 \mathrm{~mm}$, tool tip radius of the tool was decreased, value of vibration was suddenly decreased.

$\mathrm{n}=477 \mathrm{rev} / \mathrm{min}, \mathrm{f}=0.15 \mathrm{~mm} / \mathrm{rev}$, and $\mathrm{a}=0,7 \mathrm{~mm}$, tool tip radius of the tool was decreased, value of vibration was decreased.

$\mathrm{n}=477 \mathrm{rev} / \mathrm{min}, \mathrm{f}=0.25 \mathrm{~mm} / \mathrm{rev}$, and $\mathrm{a}=0,9 \mathrm{~mm}$, tool tip radius of the tool was increased 0.4 to $0.8 \mathrm{~mm}$, value of vibration was suddenly decreased; tool tip radius of the tool was increased 0.8 to $1.2 \mathrm{~mm}$, there was increased in value of vibration.

\section{Acknowledgements}

This study is supported by Scientific Research Projects Coordinators (BAP) of Selçuk University. Their support is greatly appreciated.

\section{References}

1. W. de Silva Clarence, Vibration Fundamentals and Practice, (2000). 
2. C.F. Beards, Engineering Vibration analysis with Application to control Systems, (1995).

3. H. Yunshan, G.W. Wei and Y. Xiang. DSC-Bitz method for the free vibration analysis of midline plates. Int.J.Numer.Meth.engng, 62: 262-288, (2005).

4. A. Taskesen, Computer aided nonlinear analysis of machine tool vibrations and developed computer software, Mathematical and computation Applications, 3: 377-385, (2005).

5. I. Eugene, Stiffness and damping in mechanical design, 494, (2007).

6. Y. Altintas, M.R. Khoshdarregi, Contour error control of CNC machine tools with vibration avoidance; CIRP Annals - Manufacturing Technology, 61, pp. 335-338, (2012).

7. M. A. Louroza, N. Roitmanb, C. Maglutab, Vibration reduction using passive absorption system with Coulomb damping; Mechanical Systems and Signal Processing; 19, pp. 537-549, (2005).

8. S. S. Abuthakeer, P.V. Mohanram, G. Mohan Kumar, Prediction and Contour of Cutting to Vibration in CNC Lathe with Anova and Ann; International Journal of Lean Thinking, 2, no. 1, pp. 2526-2537, (June 2011).

9. L. N. Devin and A. A. Osaghchii, Improving Performance of CBN Cutting Tools by Increasing their Damping Properties, Journal of Superhard Materials, 34, no. 5, pp. 326-335, (2012).

10. A. I. Sette, A. E. Diniz, R. Pederiva, Vibration analysis of cutting force in titanium alloy milling; International Journal of Machine Tools \& Manufacture, 50, pp. 65-74, (2010).

11. D.E. Dimla Sr., P.M. Lister, On-line metal cutting tool condition monitoring force and vibration analyses; International Journal of Machine Tools \& Manufacture, 40, pp.739-768, (2000).

12. I.A. Puertas, C.J. Luis Pérez, "Surface roughness prediction by factorial design of experiments in turning processes"; Journal of Materials Processing Technology, 143-144, 390-396, (2003).

13. A.K Ghani , I.A. Choudhury, Husni, "Study of tool life, surface roughness and vibration in machining nodular cast iron with ceramic tool"; Journal of Materials Processing Technology, 127, pp. 17-22, (2002).

14. M.E.R. Bonifacio, Diniz A.E. “ Correlating tool wear, tool life, surface roughness and vibration in finish turning with coated carbide tools"; Wear, 173, pp. 137-144, (1994).

15. M. Thomas, Y. Beauchamp, A.Y. Youssef, J. Masounave, "Effect of tool vibration during lathe dry turning process", computers Ind. Eng., 31, no. 34, pp. 637-644,1996.

16. Y. Safeen, Kassab, K.Y. Khoshnaw, "Effect of cutting tool vibration on surface roughness of work piece in dry turning operation", Eng. \& Technology, 25, no. 7. pp 123-128, (2007).

17. A.S. Adnan, S. Subbiah; "Experimental investigation of transverse vibration-assisted orthogonal cutting of AL-2024"; International Journal of Machine Tools \& Manufacture; 50, pp. 294-302, (2010).

18. B. Chen, X. Chen, B. Li, Z. He, H. Cao, GaigaiCai;"Reliability estimation for cutting tools based on logistic regression model using vibration signals"; Mechanical Systems and Signal Processing, 25, pp 2526-2537, (2011).

19. H. Wang, S. To, C. Y. Chan, C. F. Cheung, W. B. Lee; "A theoretical and experimental investigation of the tool-tip vibration and its influence upon surface generation in single-point diamond turning"; International Journal of Machine Tools \& Manufacture, 50, pp. 241-252, (2010).

20. A. Marcus, Lourozaa, N. Roitmanb, C. Maglutab; "Vibration reduction using passive absorption system with Coulomb damping"; Mechanical Systems and Signal Processing, 19, pp. 537-549, 2005. 